\title{
Social media: is it 'so yesterday'?
}

\author{
Stephen Hancocks OBE \\ Editor-in-Chief
}

The BDJ Upfront section includes editorials, letters, news, book reviews and interviews. Please direct your correspondence to the News Editor,

Kate Quinlan at BDJNews@nature.com. Press releases or articles may be edited, and should include a colour photograph if possible.

$\mathrm{S}$ ome few years ago the young son of a colleague told me in no uncertain terms how disgusted he was that his mother had signed up to a new social media site. 'It's just an embarrassment' he said with a gloomy look, 'and if you ask me it's the beginning of the end of Facebook.'

Of course the current situation with questions in Parliament, US Senate hearings and hoards of indignant users complaining is not as a result of a mother joining Facebook but rather of all the negative publicity surrounding that company and its collection, use and arguably misuse of 'our' data. As has been pointed out on many occasions, there is no such thing as a free lunch. So how do people think that social media sites are paid for? Advertising seems a possible source of income but as we have discovered, we are the 'products' and our details have been sold, exchanged, couponed, bartered and otherwise traded as potential sales leads. These are for all the things we have searched for, read, visited and otherwise shown an interest in through a multitude of sites, pages and businesses.

I have to say that I have always tried to guard what I have put on the internet, probably to little avail. So I have been somewhat surprised by the ferocious nature of the complaints by others who, up until now, had been happy enough to post images of every bowl of breakfast cereal they had ever eaten and the totality of people that they have partied with and tagged for about a decade.

Is this the beginning of the end of social media as we know it? I don't think it is, the functionality is too important, universal and (sometimes) very advantageous but I do think it will give pause for reflection as to how we use it. Companies have already started this movement. Some have pulled advertising on sites they consider no longer ethically sound. A major UK chain of pubs announced that it has ceased all its social media, linking the move to concerns regarding the misuse of personal data and the addictive nature of social media. The chairman added that while it is going against the accepted wisdom, he had always thought the idea that social media was essential for advertising was untrue and that leaving it would not adversely affect his business.

Only time will tell if he is correct but it is a significant stance against what can be seen as a previous headlong stampede to move all advertising spend away from print media to digital platforms. Perhaps it is time to regroup and assess just how cost-effective this has been and how the current bad gone on the choices we made have been vindicated and developed. But we have attempted to adapt our use of electronic media according to how readers utilise content. There is no doubt that being able to search electronically for research papers, click on links and quickly discover what it is we are seeking is a huge step forward. It is also the case that some of us still like to sit down with a print copy for an informative read, while others are happy to do the same but on an iPad, or similar.

Here at the $B D J$ we have indulged in social media to spread, very effectively, the knowledge of the journal's content and research findings and we will continue to do so. It has brought us a huge international audience and wide recognition. What we

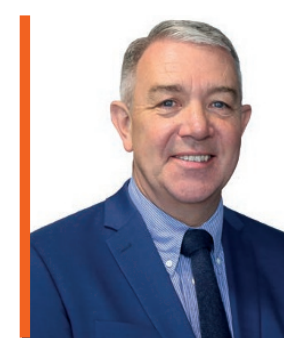

\section{'There is no such thing as a free lunch. So how do people think that social media sites are paid for?'}

press may affect the cynicism and trust of consumers in the future. The dental media has not been immune from this. Some titles have disappeared, others have gone online and struggled before they too have succumbed. For ourselves we have tried to move with the times but also to assess how best to use (and hopefully not misuse) electronic publishing and social media.

Some ten or so years ago we had to defend our strategy of putting $B D J$ research articles online together with (how dared we?) some CPD. Questions were asked in the BDA's then governing assembly, the Representative Body. Seemingly, the end of all that the profession held dear was under threat. Well, not quite and as time has also intend to continue to do is to monitor and reflect on what readers, authors and advertisers want in a journal. We do this through our newly constituted reader panel, our editorial board which includes representation of the dental industry, and through surveys and market research.

I don't think we are seeing the start of the demise of social media but I do think that what is about to be 'trending' is a greater awareness of the social responsibility that goes with it. Meanwhile, I would very much like to be able to contact the colleague's son who was so appalled with his mother but, sadly, he is no longer on Facebook.

DOI: 10.1038/sj.bdj.2018.313 